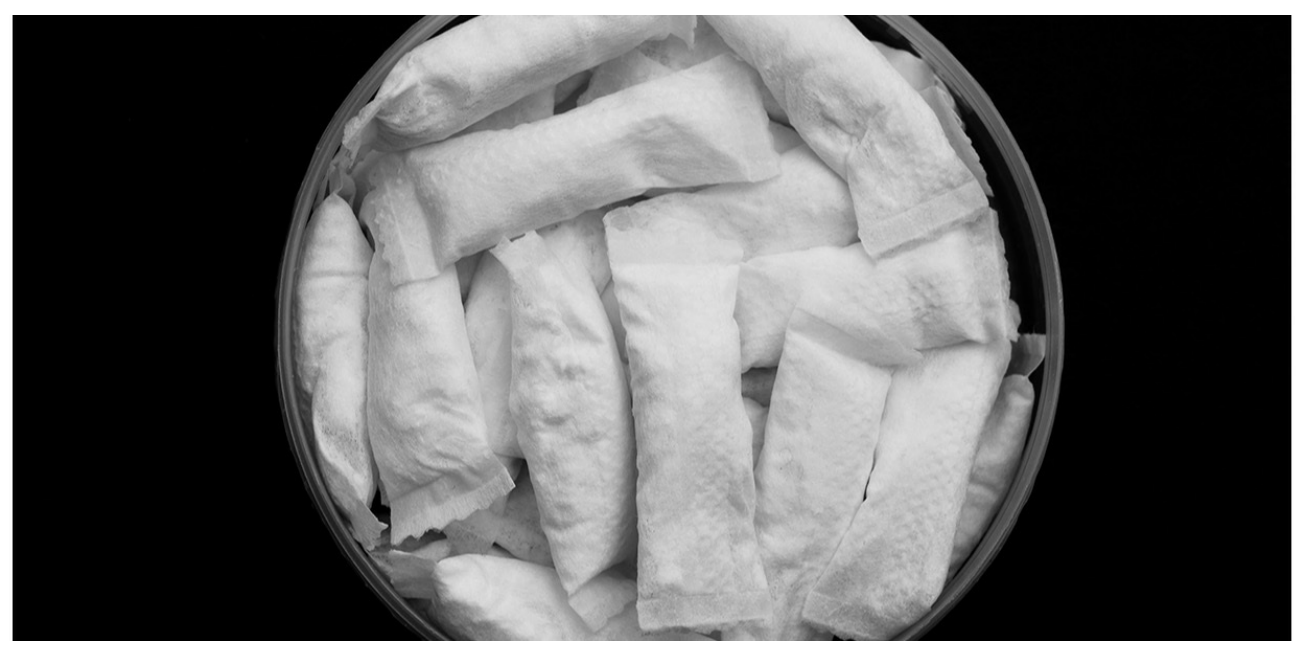

\title{
Nicotine pouches- a research and regulatory policy agenda to maximise public health benefits and minimise harms
}

\author{
Sudhanshu Patwardhan ${ }^{1}$, Karl Fagerström² \\ 1 Centre for Health Research and Education (CHRE) \\ 2 Fagerstrom Consulting
}

Funding: The authors or Centre for Health Research and Education (CHRE) did not receive any external funding for this article.

Potential competing interests: Dr Sudhanshu Patwardhan (SP) is a paid Director at Centre for Health Research and Education (CHRE), an independent healthcare company, which works on projects on smoking cessation and cancer prevention globally. CHRE has received grants from Foundation for a Smoke-free World, Inc for some of its smoking cessation projects. Previously, SP was an employee of Nicoventures, a wholly owned subsidiary of British American Tobacco, till February 2019. SP does not have any financial interest in the nicotine pouches category. Dr Fagerström has received consulting fees from many companies that develop or market pharmaceutical and behavioural treatments for smoking cessation. In year 2000 he started a company Niconovum that developed the first non-tobacco nicotine pouch that was licensed as an NRT. He currently receives consulting fees from Swedish Match and has received fees in the past from tobacco companies to assist their development of less-risky tobacco products.

\section{Abstract}

Nicotine extracted from tobacco and purified from other constituents can be delivered in the form of nicotine replacement products for helping people move away from tobacco dependence. Nicotine pouches to be put under the upper lip are one such new category of products that are being rapidly developed and marketed as consumer goods with little research or regulatory oversight. We review the available data on these products and their harm reduction potential for reducing the disease and death burden from tobacco globally. Finally, we have identified research gaps in assessing their harm and benefit potential, and possible regulatory approaches to ensure that these products do not lead to unintended consequences. 
Unburned tobacco contains about 16 carcinogens and tobacco smoke contains more than 60 , most notably tobaccospecific nitrosamines, polycyclic aromatic hydrocarbons and aromatic amines that play an important role in carcinogenesis (IARC monographs, 2021). Smoking is also associated with heart disease and chronic obstructive pulmonary disease. There are over a billion users worldwide of risky forms of tobacco, consuming tobacco in smoked forms such as cigarettes, bidis, cigars, cigarillos and/or smokeless forms such as gutkha, zarda, naswar, American chewed tobacco, etc. (WHO 2019b; GSTHR, 2020).

The main addictive component in tobacco products is nicotine and stopping nicotine can result in cravings and withdrawal symptoms. However, nicotine is not classified as a carcinogen by the WHO's International Agency for Research on Cancer (IARC monographs, 2021). According to the UK MHRA assessment, there is a large body of evidence that medicinal nicotine (in currently licensed forms) is not a significant risk factor for cardiovascular events and does not cause cancer or respiratory disease (UK Medicines and Health Regulatory Agency, 2010) and this is largely true also for Swedish snus (Lee, 2011).

Providing tobacco dependence treatment and tobacco cessation support are core to the World Health Organisation (WHO) Framework Convention on Tobacco Control's (FCTC) demand reduction and harm reduction strategies. (WHO, 2003). Article 14 of the WHO FCTC and its Guidelines call upon Parties to implement a series of measures to help tobacco users to quit tobacco. Offering help to quit tobacco use is also one of the six components of the MPOWER policy package from the Tobacco Free Initiative of the WHO intended to assist in the country-level implementation of effective interventions to reduce the demand for tobacco (WHO, 2008).

A significant proportion of current users of risky tobacco products struggle to quit without any aid. The currently available medically licensed cessation products are falling short on delivering and sustaining smoking cessation in nearly $80 \%$ of the cases where they are prescribed. To complement these current cessation aids, the principle of tobacco harm reduction (THR), where adult users of risky forms of tobacco eventually completely switch to non-combustible nicotine-containing products, can be applied to achieve and maintain cessation (Patwardhan and Rose, 2020). There is an expectation that switching to non-combustible clean nicotine-based products will lead to substantial disease risk reduction if accepted by consumers, including satisfying nicotine dose, economic feasibility, and minimal unintended consequences (Martin et al, 2004). Providing users with access to less harmful forms of nicotine could be beneficial to the users and a useful stepping stone for cessation of smoking. Over the years there has been a growing consensus to move towards the use of medicinal nicotine to minimise the harm from tobacco, starting with the 2007 Royal College of Physicians report (Royal College of Physicians, 2007). Indeed there was an acknowledgement from the other side of the Atlantic too on the principle of THR when the FDA Commissioner Dr Scott Gottlieb stated that "Nicotine, while highly addictive, is delivered through products on a continuum of risk, and that in order to successfully address cigarette addiction, we must make it possible for current adult smokers who still seek nicotine to get it from alternative and less harmful sources." (FDA, 2018). 


\section{Nicotine replacement therapy}

Nicotine replacement therapy (NRT) is a medication formulated for absorption of nicotine through the oral mucosa (chewing gum, lozenges, sublingual tablets, inhaler/inhalator, pouches), nasal mucosa (spray), or skin (transdermal patches). NRT aims to replace the nicotine, that the tobacco user would have been receiving, without the additional harmful constituents of tobacco or its combustion products. This should reduce the cravings and withdrawal symptoms, often experienced during an attempt to stop smoking, thereby increasing the likelihood of sustained abstinence (Lindson et al, 2019). NRT is effective and can significantly increase the quit rate. Besides, NRT can be expected to deliver less nicotine without any of the potentially disease-causing agents that are in tobacco smoke and, to a large extent, in smokeless tobacco too (UK Medicines and Health Regulatory Agency, 2010).

\section{NRT and regulations}

NRT products were the first and still are the only medically licensed THR options available for smoking cessation. The WHO added NRT products to the essential medicines list in 2009, underscoring the importance attributed by the WHO to medicinal nicotine as a frontline drug for cessation (WHO 2019a; Kishore et al, 2010). Many clinical guidelines recommend NRT as a first-line treatment for people seeking pharmacological help to stop smoking (Lindson et al, 2019). Also, MHRA has approved additional indications for NRT products: to cut down smoking as a stepping stone to stopping completely, for temporary abstinence and indeed for 'harm reduction' on the basis that 'there are no circumstances in which it is safer to smoke than to use NRT"(UK Medicines and Health Regulatory Agency, 2010).

\section{Safety and efficacy of available NRT formulations}

Apart from its consumption through tobacco products, nicotine is used by adults worldwide in the form of skin patches, chewing gum, pouches, nasal and oral sprays, inhalers, lozenges and tablets. In many countries, users can get NRT from healthcare professionals as well as over-the-counter, without prescriptions. Table 1summarizes the products currently licensed in the UK.

\section{Table $1 \quad$ Nicotine replacement therapies available in the UK}




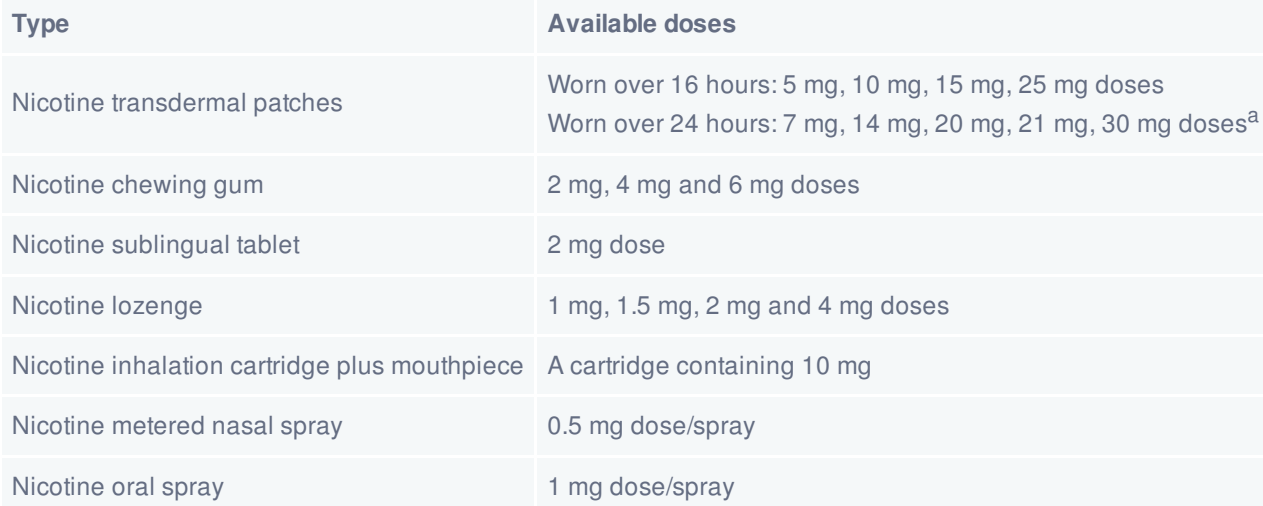

Information extracted from British National Formulary; (Lindson et al, 2019)

a $35 \mathrm{mg} / 24$-hour and $53.5 \mathrm{mg} / 24$-hour patches available in other regions.

NRT is a safe and effective treatment for quitting smoking. People are somewhat more likely to quit with a higher dose of NRT as compared with a lower dose of NRT (Lindson et al, 2019). However, none of the available NRT products deliver such high doses of nicotine and as quickly as cigarettes. The average cigarette delivers between 1 and $3 \mathrm{mg}$ of nicotine and the typical pack-a-day smoker absorbs 20 to $40 \mathrm{mg}$ of nicotine each day (Henningfield et al, 2005). Offering NRT to dependent smokers, who are prepared to try to quit, increases their chance of success over that achieved with the same level of support but without NRT.

In general, with the available evidence, there have been no safety concerns identified after the use of various forms of NRTs (Murray et al. 2009, Lindson et al, 2019).

\section{Oral nicotine pouch - newer nicotine replacement formulation}

New non-combustible consumer products containing nicotine are rapidly entering the market. Examples of new product categories are electronic cigarettes, heat-not-burn products, and nicotine pouches. This paper reviews the oral nicotine pouches category.

Oral nicotine pouches (Figure 1) are similar in appearance to an established form of smokeless tobacco product commonly used in Scandinavia called 'snus'. Swedish-style snus is a type of heat-treated and pouched smokeless tobacco that does not produce excessive salivation making it spit-less. The nicotine pouch products are placed, like Swedish snus, between the upper lip and gum. The nicotine pouches are different to Swedish-style snus in that there is no leaf tobacco in them. The precursor of today's nicotine pouches was studied in clinical studies as a new formulation for nicotine replacement treatment under the Zonnic brand in the late 2000s (Thornley et al, 2009) and the manufacturer Niconovum was given marketing authorisation for the product as a medically licensed NRT in Sweden in 2012 and is currently available in all Nordic Countries. 
Nicotine pouches are also called modern oral nicotine products. For the purpose of this paper, we use the term nicotine pouches for consistency and due to the descriptive self-evident nature of the term. In its latest version as a consumer good, the first nicotine pouch to be widely distributed in the USA was branded ZYN, which was test-marketed in Colorado in 2014 by Swedish Match North America (SMNA) with the nationwide distribution available by April 2019. ZYN is a thin white pouch that contains white powdered nicotine in strengths of 3 and $6 \mathrm{mg}$. Other ingredients in ZYN include foodgrade additives, fillers, a stabilizer (hydroxypropyl cellulose), pH adjusters, noncaloric sweeteners, and flavourings (cool mint, peppermint, citrus, wintergreen, spearmint, cinnamon, and coffee). The pouch is meant to be placed inside the fold of the upper lip for a duration of 30-60 minutes. (zyn.com; Plurphanswat et al., 2020). It is also available in some European countries.

Figure $1 \quad$ Nicotine pouch: appearance and size

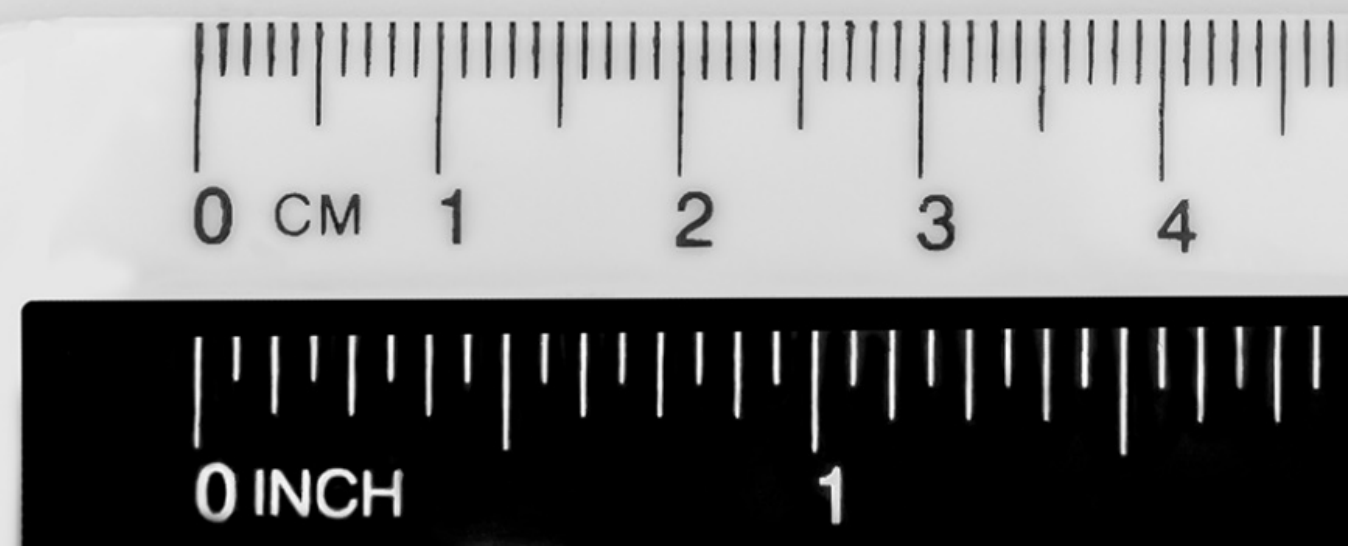

\section{Current market data}

The global brand and manufacturer landscape for the nicotine pouch category is rapidly evolving. Currently available brands for nicotine pouch are listed in Table 2. The respective manufacturers claim that none of their brands contains tobacco. 
Table 2

List of Available Brands for Nicotine Pouch

\begin{tabular}{|l|l|l|l|}
\hline Brand & Manufacturer & Country & Nicotine level \\
\hline 2one (Twenty One) & 2ONE Labs & USA & $3,6,8 \mathrm{mg}$ \\
\hline Dryft & Kretek International & USA & $2,4,7 \mathrm{mg}$ \\
\hline Loop & Another Snus Factory & EU & $6,9,11,12.5 \mathrm{mg}$ \\
\hline Lyft & British American Tobacco & Iceland, Sweden and UK & $4,6 \mathrm{mg}$ \\
\hline Nordic Spirit & Japan Tobacco International & Sweden, Switzerland and UK & $6,9,11 \mathrm{mg}$ \\
\hline On! & Altria & Japan, Sweden and USA & $1.5,2,3.5,4$, and $8 \mathrm{mg}$ \\
\hline Rogue & Swisher International & USA & $3,6 \mathrm{mg}$ \\
\hline Rush & Alternative Nicotine Technologies & USA & $3,7 \mathrm{mg}$ \\
\hline Velo & R. J. Reynolds Vapor Company & USA & $4,6,10,11 \mathrm{mg}$ \\
\hline ZoneX & Imperial Tobacco & UK & $6,10 \mathrm{mg}$ \\
\hline Zyn & Swedish Match & EU and USA & 3 and $6 \mathrm{mg}$ \\
\hline
\end{tabular}

Source: individual product websites, April 2021

US market data suggests that the average weekly volume of nicotine pouches sold had gone up from 99,000 units in January 2018 to more than 2.5 million as of mid-July 2020 (Prokop, 2020). As per available market research data, while unit sales for cigarettes fell more than $4 \%$ in 2019, spitless tobacco unit sales were growing by more than $44 \%$ (Abcede, 2020). Even during the COVID-19 pandemic, for the four weeks ending April 19, 2020, spitless tobacco sell went up by $80.6 \%$ while cigarettes dropped $2.4 \%$, and e-cigs declined $1.1 \%$ for the same period. Nielsen data showed e-cigs down 8.5\% and cigarettes down 5\% for the four weeks ending April 25, 2020 (Del Conte, 2020).

In the US, for the 24 weeks ending on May 30, 2020, nicotine pouches grew by $498 \%$. Top brands and their sales for the four weeks ending on July 11, 2020, were as follows (Prokop, 2020):

- Zyn (8.3 million units).

- On, Richmond, Va.-based Altria Group (1.4 million units).

- Rogue, from Jacksonville, Fla.-based Swisher International (615,000 units).

- Velo, from Winston-Salem, N.C.-based R.J. Reynolds Vapor Co. (607,000 units).

- Dryft, from Moorpark, Calif.-based Kretek International (175,000 units).

\section{Current publicly available research data}

Based on a PubMed search (on April 08, 2021) using "nicotine pouches and products", 6 relevant articles were obtained.

Table 3

Current Publicly Available Research Data on Nicotine Pouches 


\begin{tabular}{|c|c|c|c|c|}
\hline Title & Authors & $\begin{array}{l}\text { Year of } \\
\text { publication }\end{array}$ & $\begin{array}{l}\text { Type of article } \\
\text { (original } \\
\text { research/opinion } \\
\text { piece) }\end{array}$ & $\begin{array}{l}\text { Journal } \\
\text { reference }\end{array}$ \\
\hline Initial Information on a Novel Nicotine Product & $\begin{array}{l}\text { Plurphanswat N, Hughes JR, Fagerström } \\
\text { K, Rodu B }\end{array}$ & 2020 & Original research & $\begin{array}{l}\text { Am J Addict. } \\
2020 \\
\text { Jul;29(4):279- } \\
286\end{array}$ \\
\hline $\begin{array}{l}\text { Pharmacokinetic Comparison of a Novel Non-tobacco- } \\
\text { Based Nicotine Pouch (ZYN) With Conventional, Tobacco- } \\
\text { Based Swedish Snus and American Moist Snuff }\end{array}$ & $\begin{array}{l}\text { Lunell E, Fagerström K, Hughes J, Pendrill } \\
\text { R }\end{array}$ & 2020 & Original research & $\begin{array}{l}\text { Nicotine Tob } \\
\text { Res. } 2020 \text { Oct } \\
8 ; 22(10): 1757 \text { - } \\
1763\end{array}$ \\
\hline Nicotine pouches & Keogh A & 2021 & $\begin{array}{l}\text { Opinion piece } \\
\text { (letter to the } \\
\text { editor) }\end{array}$ & $\begin{array}{l}\text { Br Dent J. } 2021 \\
\text { Jan;230(2):61-62 }\end{array}$ \\
\hline $\begin{array}{l}\text { A single-blind, randomized, crossover trial of the effects of } \\
\text { a nicotine pouch on the relief of tobacco withdrawal } \\
\text { symptoms and user satisfaction. }\end{array}$ & $\begin{array}{l}\text { Thornley S, McRobbie H, Lin RB, Bullen C, } \\
\text { Hajek P, Laugesen M, Senior H, Whittaker } \\
\text { R }\end{array}$ & 2009 & Original research & $\begin{array}{l}\text { Nicotine Tob } \\
\text { Res. } 2009 \\
\text { Jun;11(6):715-21 }\end{array}$ \\
\hline $\begin{array}{l}\text { Tobacco companies introduce 'tobacco-free' nicotine } \\
\text { pouches }\end{array}$ & Robichaud MO, Seidenberg AB, Byron MJ & 2020 & Opinion piece & $\begin{array}{l}\text { Tob Control. } \\
2020 \\
\text { Dec;29(e1):e145- } \\
\text { e146 }\end{array}$ \\
\hline $\begin{array}{l}\text { An approach for the extract generation and toxicological } \\
\text { assessment of tobacco-free 'modern' oral nicotine pouches }\end{array}$ & $\begin{array}{l}\text { Bishop E, East N, Bozhilova S, Santopietro } \\
\text { S, Smart D, Taylor M, Meredith S, Baxter A, } \\
\text { Breheny D, Thorne D, Gaca M }\end{array}$ & 2020 & $\begin{array}{l}\text { Original research } \\
\text { (Methods paper) }\end{array}$ & $\begin{array}{l}\text { Food Chem } \\
\text { Toxicol. } 2020 \\
\text { Nov;145:111713 }\end{array}$ \\
\hline $\begin{array}{l}\text { A screening approach for the evaluation of tobacco-free } \\
\text { 'modern oral' nicotine products using Real-Time Cell } \\
\text { Analysis }\end{array}$ & $\begin{array}{l}\text { East N, Bishop E, Breheny D, Gaca M, } \\
\text { Thorne D }\end{array}$ & 2021 & $\begin{array}{l}\text { Original research } \\
\text { (Methods paper) }\end{array}$ & $\begin{array}{l}\text { Toxicol Rep. } \\
2021 \text { Feb } \\
25 ; 8: 481-488\end{array}$ \\
\hline
\end{tabular}

The only peer-reviewed published pharmacokinetics study on nicotine pouches showed that despite a lower nicotine content, the non-tobacco-based ZYN $6 \mathrm{mg}$ product gave rise to a significantly larger uptake of nicotine to the systemic blood circulation, measured as $\mathrm{AUC}_{\text {inf }}$, than did the conventional, tobacco-based $8 \mathrm{mg}$ General snus. Conventional, tobacco-based General snus ( $8 \mathrm{mg}$ ) gave rise to significantly larger nicotine extraction and subsequent uptake in the systemic blood circulation than did the non-tobacco-based ZYN $3 \mathrm{mg}$ product. ZYN 8mg delivers similar amounts of nicotine as the Longhorn Natural moist snuff (18mg), but significantly less than two pouches of General snus (2x8mg). In summary, the two higher doses of ZYN (6 mg and $8 \mathrm{mg}$ ) deliver nicotine as quickly and to a similar concentration compared to existing smokeless products, with no significant adverse effects. In this study, the authors have included a reference to a $4 \mathrm{mg}$ nicotine gum which delivered less nicotine than any of the other products. This suggests their efficacy in reducing withdrawal symptoms and helping smokers reduce or stop combustible tobacco use should be similar or better than NRT products (Lunell et al., 2020).

The other study that assessed consumer insights and interaction with one of the current nicotine pouch products on the market showed that the labelling and packaging of the product were such that almost $90 \%$ of never and former users did not find it to be appealing. Only $3 \%$ of never users and $2 \%$ of former users were interested in buying the product (Plurphanswat et al., 2020). According to the study, the current demographics of product users consisted of an educated, working adult population with an average age of about 33 years, completed at least a high school diploma with an income 
of more than $\$ 50000$. The majority of users were current smokeless tobacco (ST) users and former tobacco users due to its use - placing the product between the lip and gum - is similar to other ST products. According to the study, the pouches were co-located in the ST section at retail by the manufacturer. The most common reasons for use of the product among current ST users were "less harmful...," "no one can tell when using," and "to avoid spitting." Among current other tobacco users, the most popular reasons were "less harmful to my health than other tobacco products." "Less harmful for my health than cigarettes" and "do not cause me to smell like smoke/tobacco" were the top answers among current smokers. For former users, "less harmful than other tobacco and cigarettes" and "no smell like smoke/tobacco" were the common reasons. The above findings seem to involve little unintended use. However, the situation in which the pouches exist may change. From a product new to the market with limited reach and sales to a product more visible due to advertising, may change the attitude to the pouch category among non-nicotine users. The marketing practices may become more aggressive and directed to adolescents. To identify and address unintended consequences in a timely manner, further use studies and ongoing monitoring of these products is called for. Already, as per some investigative media reports, some of the manufacturers are practising unethical market approach and targeting non-users and vulnerable young population for the sale of nicotine products (Chapman, 2021; Davis and Chapman, 2021). This brings into question the suitable regulatory regime for these products and the research gaps that need to be plugged in so as to inform a science-driven regulatory policy.

\section{Current regulatory landscape}

As they do not contain tobacco, nicotine pouches are currently being sold as consumer products in the UK and not included under the regulations derived from the EU Tobacco Products Directive (2014/40/EU). The nicotine pouches currently sold in the USA do not make any cessation claims and fall under the regulatory purview of the FDA Center for Tobacco Products (CTP). Under FDA rules, as these products do not contain leaf tobacco they are not classified as smokeless tobacco. As with other tobacco products regulated by the FDA CTP, manufacturers with nicotine pouches already on the market in the US were expected to submit their Premarket Tobacco Product Applications (PMTA) before the stipulated deadline of September 09, 2020 (Reynolds American Inc., 2020). To the authors' knowledge, there is no specific guidance on nicotine pouch category-specific requirements for PMTA submission. Broad requirements include the use of nicotine warning labels and compliance with some basic marketing restrictions. In the rest of the world, a launch of these products with little or no dialogue or buy-in with local public health experts, consumers, healthcare professionals and regulators, is leading to concerns from those in tobacco control (Chapman, 2021; Rob and Chapman, 2021).

\section{Discussion}

There are well over a billion current tobacco users globally, and even with the best of tobacco control measures to prevent initiation among a new generation of users, the disease and death burden from current tobacco use is expected to continue over the next three decades (Yach, 2020). This will be particularly true if adequate behavioural support and THR choices are not available. As healthcare scientists, the authors would like to see adult users of risky tobacco products to have 
credible, viable and safer alternatives to their current addiction. Based on the claimed product chemistry, nicotine pouches can be reasonably expected to be of harm reduction potential if used for complete substitution by current users of risky forms of smoked and smokeless tobacco. However, consumers, regulators as well as healthcare professionals would need much more information than currently available to be confident about the net potential benefit of a new nicotine product category such as nicotine pouches.

\section{Lessons from other new nicotine products}

Electronic Nicotine Delivery Systems (ENDS) or e-cigarettes are a category of nicotine products that have been in the market for less than two decades. With an estimated 68 million current users of e-cigarettes, most of them past cigarette smokers (GSTHR, 2020), e-cigarettes are considered to have harm reduction potential (Public Health England, 2021). Ecigarettes are regulated alongside tobacco products in countries such as the USA, Canada, UK and the common market of the European Union. Elsewhere, these products are yet to come under any specific regulatory regime, although there are draft proposals, for example, in China (Reuters, 2021). However, a range of developments such as e-cigarette marketing practices particularly to the youth, risk of youth uptake, lack of availability of adequate clinical studies to unequivocally prove e-cigarettes' role in cessation and relapse prevention, the chemistry profile of the e-cigarette aerosol in certain extreme use conditions and the acquisition of e-cigarette companies by transnational tobacco companies have led to concerns about e-cigarettes' safety, efficacy, intended use or net public health benefit. E-cigarettes are now banned or require medical licensing in over 30 countries, including countries such as India, Singapore and Australia (GSHTR, 2020). Such opposite approaches to the understanding and regulation of e-cigarettes may be symptomatic of the conflicting agendas of those in public health, the tobacco and pharmaceutical industries, and the regulators. The case, for regulating and allowing e-cigarettes for smoking cessation as a harm reduction tool among smokers, is lost among the concerns for preventing initiation among a new generation of nicotine users. This has obvious implications for the nicotine pouches category.

\section{Concerns with nicotine pouches:}

Oral nicotine pouches come in an array of flavours such as mango, cinnamon, honey lemon, citrus burst, black cherry and many types of mint and menthol flavours. Tobacco control advocates believe that flavours play a significant role in drawing youth to tobacco products so much that up to $80 \%$ of youth who have used tobacco report that they began with a flavoured product (Truth Initiative, 2021). According to them, for a large majority of users, flavouring is a primary reason to use the products.

An escalating 'nicotine strength' war is another matter of concern. Around 2018, in Russia and some Eastern European countries, pouches were increasingly sold in much higher strengths (>20 mg/pouch) than needed for craving relief and withdrawal management in tobacco cessation. The nicotine pouches category is now banned in Russia. (Tobacco Intelligence, 2020). 


\title{
Research gaps
}

The few studies published so far are helpful in beginning to get insights into nicotine uptake, consumer profile and preferences. Large gaps in research still remain, before regulators, public health and consumers can accept these as harm reduction products. In order to be appropriate for the protection of public health the following research areas would give valuable insights for regulation and consumer information (Table 4):

\section{Table $4 \quad$ Research Agenda for Nicotine Pouches}

\author{
Product chemistry \\ The product chemistry should be characterised with special emphasis on the flavourings' potential for toxic effects.

\section{Pharmacokinetics} \\ The pharmacokinetics should be characterised for different doses of nicotine and for different additives to the product that can alter the pH and the taste profile \\ What is the absolute and relative safety of the actual product itself? \\ For example, on the oral mucosa. If the product is marketed to users of risky forms of tobacco, it would be important to compare the product's safety with that of \\ those products, in those relevant countries and populations. \\ What is the acceptable maximum level of nicotine per pouch that can achieve its stated public health goal? \\ Since some of these products sold in certain countries had significantly higher doses of nicotine than seen with licensed medicinal nicotine replacement \\ products, there might be a need to have a limit on the nicotine dose taking into account the nicotine's release and absorption from the product. \\ Is the communication around the use of the product appropriately understood? \\ For example, that the pouches should be marketed and sold for use by current or former users of risky tobacco for complete substitution and not used to be \\ together for long durations ("dual/poly use").
}

Who are the intended consumers?

For example, that the pouches should be marketed solely to adult current and former users of risky tobacco products to quit their risky habit or prevent relapse of the risky habit, respectively

What is the likelihood of unintended use in the population?

For example, if it is used by non-tobacco users and especially taken up by nicotine-naïve adolescents? If such uptake occurs it would be important to know if it is a gateway to other tobacco use and is the risk of such a gateway statistically significant at a population level.

What is the transition time for current users to switch over to the product?

Understandably there may be a transition time among current users of risky tobacco products from nicotine pouch trial, to a phase of dual use (e.g. less than a year), to complete switch to pouches. That time needs to be understood, confirmed in large scale studies and communicated.

Do these products deter or delay intentions to completely give up tobacco and nicotine use?

It will be important to study whether the marketing, sale and use of these products undermine individual level and population level attempts to quit risky forms of tobacco

Product abuse liability

Abuse liability should be studied preferably in comparison with other categories like cigarette smoking and smokeless tobacco.

\section{Regulatory approach: Distribution and access}

A globally consistent approach to regulating non-combustible, safer nicotine products with harm reduction potential, would be ideal so as to share learnings, achieve greater success in the implementation of Article 14 of the FCTC and achieve public health goals of tobacco control as defined in the FCTC text. Nicotine replacement therapy products are already on the WHO's model essential medicines list. First, innovative products such as nicotine pouches need to satisfy regulators, 
healthcare professionals and current consumers of risky tobacco products on their safety, efficacy and appeal, respectively. Then, the key to maximise their harm reduction potential is by ensuring consumer access, affordability and availability. This should not, however, come at the cost of ease of access to youth and non-users of nicotine and tobacco. In the UK, medically licensed NRT products are available on the 'general sales list' and allowed for a wide range of harm reduction related indications. UK's current NRT product regulations can be said to achieve the regulatory 'sweet-spot' that allows a breadth of access to the target user population, whilst limiting unintended consequences.

Due to the idiosyncrasies of historical distribution channels, a clear division between tobacco and pharmacy licensed shops (for example, Southern European countries) may mean that potential harm reduction products such as nicotine pouches may fall through the cracks, and a binary choice of distribution channel may limit access and availability to the consumers who need it in the rest of the world.

The COVID-19 pandemic has changed consumer purchase behaviour globally, thus potentially providing newer ways for consumers to access nicotine pouches through online retailers. This increases access but also brings with it the risk of youth marketing and purchase. The UK's Digital Policy Alliance with the British Standards Institute has set out the code of practice in the BSI PAS 1296 (British Standards Institute, 2018), and could be an example for age checking tools and requirements to ensure that the online purchaser as well as the one receiving the delivery is a verified adult.

\section{Nicotine literacy among influencers and decision makers}

The authors believe that the THR principle is clearly articulated and accepted by regulators on both sides of the Atlantic and indeed the original text of the WHO FCTC. Reducing the adverse impact of tobacco on health should be a high priority for policymakers and their influencers, including, health care professionals. In a rapidly developing area such as innovative nicotine products, it is not surprising that regulators play catch up. However, a big hurdle to the acceptance of these products globally and especially among healthcare professionals and by extension, the lay public, is the prevalent nicotine illiteracy (Patwardhan et al., 2020; FSFW, 2019; Steinberg et al., 2020).

As long as key influencers and decisionmakers wrongly consider nicotine in tobacco products to be carcinogenic and do not comprehend that nicotine can be used relatively safely for craving relief and withdrawal management for as long as necessary by those struggling to quit risky tobacco without any aid, a launch of new products such as nicotine pouches is bound to evoke a negative knee jerk response.

We envisage a check-list of triggers and actions relevant to specific stakeholder groups, so as to achieve an aligned THRdriven vision in nicotine pouches' regulatory policy globally.

Table 5 Stakeholder Matrix for maximising the THR potential of Nicotine Pouches 


\begin{tabular}{|l|l|}
\hline $\begin{array}{l}\text { Stakeholder Group } \\
\begin{array}{l}\text { Regulators and } \\
\text { Policymakers }\end{array}\end{array}$ & Selps buy-in \\
\hline $\begin{array}{l}\text { Public Health } \\
\text { Clearly targeted for tobacco cessation among current } \\
\text { users of risky tobacco }\end{array}$ \\
\hline $\begin{array}{l}\text { Healthcare } \\
\text { practitioners }\end{array}$ & Nicotine literacy \\
\hline Consumers & $\begin{array}{l}\text { Affordable, appealing, available and accessible } \\
\text { products }\end{array}$ \\
\hline Manufacturers & Responsible marketing and duty of care research \\
\hline
\end{tabular}

Brings in rejection or ban

Media scare stories, economic factors (e.g. lack of cigarette revenue/tax)

Seen as normalising tobacco use, targeting youth, prolonged dual use

Bad experience with failed cessation attempts with inferior products, poor support and media scare stories

High cost, scare stories, poor appeal, tastelessness, association with stigma and overly medicalised

Used for undermining tobacco control policies

Indeed, globally, responsible manufacturers have a duty of care to address the prevalent research gaps as well as plug the knowledge gaps around nicotine and THR among key stakeholder groups. Such an approach has the potential to accelerate the delivery of a wider range of affordable cessation tools to Low-and-middle-income countries (LMICs), e.g. India. India has the highest prevalence of oral cancers worldwide, driven largely by a vast array of risky smokeless tobacco products. With around 200 million current smokeless tobacco users there is a great challenge and opportunity in India to bring responsibly manufactured and marketed products such as affordable nicotine pouches made for the masses.

\section{Conclusion}

A properly regulated, affordable, accessible and appealing nicotine pouch category specifically targeted to current tobacco users as a cessation tool is much needed. A comprehensive research and nicotine education agenda will need to be prioritised by all stakeholders to maximise this category's public health potential and minimise its unintended consequences.

\section{References}

Abecede, Angel (2020). Tobacco Sales: Where the Gains Are. CSP, 9 April 2020. Available at: https://www.cspdailynews.com/tobacco/tobacco-sales-where-gains-are(accessed 13 April 2021).

Action on Smoking and Health (2021). Harm Reduction. Available at: https://ash.org.uk/category/information-andresources/product-regulation/harm-

reduction/\#: :text=Tobacco\%20harm\%20reduction\%20within\%20a,to\%20smoking\%20cessation\%20see\%3A\%20Smokin g (accessed 13 April 2021).

British Standards Institute (2018). New guidance to protect children from viewing adult content online. Available at: https://www.bsigroup.com/en-GB/about-bsi/media-centre/press-releases/2018/may/new-guidance-to-protect-children-fromviewing-adult-content-online/ (accessed 13 April 2021). 
Chapman, Matthew (2021). New products, old tricks? Concerns big tobacco is targeting youngsters. The Bureau of Investigative Journalism, 21 February 2021. Available at: https://www.thebureauinvestigates.com/stories/2021-02-21/newproducts-old-tricks-concerns-big-tobacco-is-targeting-youngsters (accessed 13 April 2021).

Davies, Rob and Chapman, Matthew (2021). Tobacco giant bets $£ 1$ bn on influencers to boost 'more lung-friendly' sales. Th Guardian, 20 February 2021. Available at: https://www.theguardian.com/business/2021/feb/20/tobacco-giant-bets-1bnon-social-media-influencers-to-boost-lung-friendlier-sales (accessed 25 February 2021).

Del Conte, Erin (2020). Tobacco's 2020 Trajectory. 8 June 2020. Available at: https://cstoredecisions.com/2020/06/08/tobaccos-2020-trajectory/(accessed 13 April 2021).

FDA (2018). Statement from FDA Commissioner Scott Gottlieb, M.D., on pivotal public health step to dramatically reduce smoking rates by lowering nicotine in combustible cigarettes to minimally or non-addictive levels. Available at: https://www.fda.gov/news-events/press-announcements/statement-fda-commissioner-scott-gottlieb-md-pivotal-publichealth-step-dramatically-reduce-smoking (accessed 13 April 2021).

FSFW (2019). Global State of Smoking Poll 2019 by Foundation for a Smoke-Free World. Available at: https://www.smokefreeworld.org/global-state-of-smoking-poll-2019/ (accessed 13 April 2021).

GSTHR (2020). Burning Issues: Global State of Tobacco Harm Reduction 2020. Available at: https://gsthr.org/report/2020/burning-issues (accessed 13 April 2021).

Henningfield JE, Fant RV, Buchhalter AR, Stitzer ML (2005). Pharmacotherapy for nicotine dependence. CA Cancer Journal for Clinicians 2005;55(5):281-99.

IARC Monographs (2021). IARC monographs on the identification of carcinogenic hazards to humans, WHO. Available at: https://monographs. iarc.fr/list-of-classifications (accessed 24 February 2021).

Kishore, S.P., Bitton, A., Cravioto, A. and Yach, D. (2010). Enabling access to new WHO essential medicines: the case for nicotine replacement therapies. Globalization and Health, Vol. 6 No. 1, Article number: 22.

Lee, $\mathrm{P}$ (2011). Summary of the epidemiological evidence relating snus to health. Regul Toxicol Pharmacol. 2011 Mar;59(2):197-214. doi: 10.1016/j.yrtph.2010.12.002. Epub 2010 Dec 14.

Lindson N, Chepkin SC, Ye W, Fanshawe TR, Bullen C, Hartmann-Boyce J (2019). Different doses, durations and modes of delivery of nicotine replacement therapy for smoking cessation. Cochrane Database of Systematic Reviews 2019, Issue 4. Art. No.: CD013308. DOI: 10.1002/14651858.CD013308 (accessed 13 April 2021). 
Lunell E, Fagerström K, Hughes J, Pendrill R (2020). Pharmacokinetic Comparison of a Novel Non-tobacco-Based Nicotine Pouch (ZYN) With Conventional, Tobacco-Based Swedish Snus and American Moist Snuff. Nicotine Tob Res. 2020 Oct 8;22(10):1757-1763. doi: 10.1093/ntr/ntaa068. PMID: 32319528.

Martin EG, Warner KE, Lantz PM (2004). Tobacco harm reduction: what do the experts think? Tobacco Control 2004;13:123-128.

Murray, R., Connett, J. and Zapawa, L. (2009). Does nicotine replacement therapy cause cancer? Evidence from the lung health study. Nicotine Tob Res. 2009 Sept 11; (9): 1076-1082. Doi:10.1093/ntr/ntp104.Epub2009 Jul 1.

Patwardhan S and Rose JE (2020). Overcoming barriers to disseminate effective smoking cessation treatments globally. Drugs and Alcohol Today 2020;20(3):235-247.

Patwardhan S. Sucharitha ST, Arumugam B, Kale G, Sharan RN (2020). A Pilot Study to Assess the Knowledge, Attitude and Practice Among Healthcare Practitioners in India Regarding Tobacco Use and Cessation. Indian Journal of Clinical Practice, 31(2):120-130.

Plurphanswat, N., Hughes, J.R., Fagerström, K. and Rodu, B. (2020), Initial Information on a Novel Nicotine Product. Am J Addict, 29: 279-286. https://doi.org/10.1111/ajad.13020

Prokop, Hannah (2020). Nicotine Pouches: Tobacco's Fast-Growing Subcategory. CSP, 16 October 2020. Available at: https://www.cspdailynews.com/tobacco/nicotine-pouches-tobaccos-fast-growing-subcategory (accessed 13 April 2021).

Public Health England (2021). Vaping in England: an evidence update including vaping for smoking cessation. Available at:

https://assets.publishing.service.gov.uk/government/uploads/system/uploads/attachment_data/file/962221/Vaping_in_Engl and evidence update February 2021.pdf(accessed 9 April 2021).

Reuters (2021). China mulls bringing e-cigarette regulation in line with traditional tobacco products. Reuters March 22, 2021, Available at: https://www.reuters.com/article/us-china-tobacco-idUSKBN2BE124 (accessed 13 April 2021).

Reynolds American Inc (2020). VELO Pouch Premarket Tobacco Applications Submitted to FDA for Review by Reynolds, Press release, September 01, 2020. Available at: https://www.prnewswire.com/news-releases/velo-pouch-premarkettobacco-applications-submitted-to-fda-for-review-by-reynolds-301122281.html (Accessed 13 April 2021).

Royal College of Physicians (2007). Harm reduction in nicotine addiction: helping people who can't quit. Available at: 
https://shop.rcplondon.ac.uk/products/harm-reduction-in-nicotine-addiction-helping-people-who-cant-quit? variant=6509405637 (accessed 13 April 2021).

Steinberg MB, Bover Manderski MT, Wackowski OA, Singh B, Strasser AA, Delnevo CD (2020). Nicotine Risk Misperception Among US Physicians. J Gen Intern Med. 2020 Sep 1. doi: 10.1007/s11606-020-06172-8. Epub ahead of print.

Thornley S, McRobbie H, Lin RB, Bullen C, Hajek P, Laugesen M, Senior H, Whittaker R (2009). A single-blind, randomized, crossover trial of the effects of a nicotine pouch on the relief of tobacco withdrawal symptoms and user satisfaction. Nicotine Tob Res. 2009 Jun;11(6):715-21. doi: 10.1093/ntr/ntp054.

Tobacco Intelligence (2020). Regulatory Briefing: Russian Duma passes bill banning tobacco-free white pouches, Available at: https://tobaccointelligence.com/russia-gives-green-light-to-ban-tobacco-free-white-pouches/ (accessed 13 April 2021).

Truth Initiative (2021). What is Zyn and what are oral nicotine pouches? Available at: https://truthinitiative.org/researchresources/emerging-tobacco-products/what-zyn-and-what-are-oral-nicotine-pouches (accessed 13 April 2021).

UK Medicines and Health Regulatory Agency (2010). Public Assessment Report: The use of nicotine replacement therapy to reduce harm in smokers. February 2010. Available at: https://assets.publishing.service.gov.uk/ government/uploads/system/uploads/attachment_data/ file/853861/Nicotine_replacement_therapy_harm_ reduction_in_smokers.pdf (accessed 13 April 2021).

WHO (2003). Framework Convention on Tobacco Control. Available at: http://apps.who.int/iris/bitstream/10665/42811/1/9241591013.pdf?ua=1 (accessed 13 April 2021).

WHO (2008), "WHO report on the global tobacco epidemic. The MPOWER package", Available at: https://apps.who.int/iris/bitstream/handle/10665/43818/9789241596282_eng.pdf?sequence=1 (accessed 13 April 2021).

WHO (2019a), "WHO model list of essential medicines", available at:

https://www.who.int/medicines/publications/essentialmedicines/en/ (accessed 13 April 2021).

WHO (2019b). WHO global report on trends in prevalence of tobacco use 2000-2025, third edition. (2019). World Health Organization. https://www.who.int/publications//item/who-global-report-on-trends-in-prevalence-of-tobacco-use-20002025-third-edition (accessed 13 April 2021).

Yach, Derek (2020). Accelerating an end to smoking: a call to action on the eve of the FCTC's COP9. Drugs and Alcohol 
Today 2020;20(3):173-189. 